\title{
DOES PNEUMONECTOMY FOR LUNG CANCER ADVERSELY INFLUENCE LONG-TERM SURVIVAL?
}

Mark K. Ferguson, MD

Theodore Karrison, $\mathrm{PhD}$
Objective: The increased operative mortality associated with pneumonectomy has stimulated the use of lung-sparing operations such as sleeve lobectomy. Whether pneumonectomy adversely affects long-term outcome after lung resection is unknown. Methods: We reviewed the cases of patients who underwent lobectomy/bilobectomy or pneumonectomy because of non-small cell lung cancer between January 1980 and June 1998. Survival curves were compared by the log-rank test. Covariates were determined for operative mortality and survival using logistic regression analysis and Cox proportional hazards estimation, respectively. Results: There were 259 men and 183 women who underwent lobectomy/bilobectomy (340) or pneumonectomy (102). Operative mortality was $36(8.1 \%)$ patients overall, $24(7.0 \%)$ for lobectomy/bilobectomy and $12(12 \%)$ for pneumonectomy. Mean follow-up was 41 months (range 0-222 months). Median survival was worse for pneumonectomy (stage II: 17.9 vs 36.3 months, $\log$-rank $P=.05$; stage III: 11.7 vs 21.3 months, log-rank $P=.07$ ). However, important covariates for survival were age, primary tumor status, regional nodal status, and forced expiratory volume in 1 second. After adjusting for these covariates, survival did not differ significantly between the types of operations (hazard ratio for pneumonectomy 1.21; 95\% CI 0.88-1.68). Conclusions: We did not detect a significant long-term adverse influence of pneumonectomy on survival after adjusting for other prognostic factors, but randomized clinical trials would be needed to definitively address this issue. ( $J$ Thorac Cardiovasc Surg 2000;119:440-8)
$T^{n}$ he appropriate extent of parenchymal resection in the treatment of lung cancer remains controversial. For decades pneumonectomy has been the operation of choice for central or locally advanced tumors. During the past two decades there has been a growing experience with the use of parenchyma-sparing techniques such as sleeve lobectomy in the management of this subgroup of cancers. The indications for the use of such procedures are not well defined but include anatomical-

From the Departments of Surgery and Health Studies, The University of Chicago, Chicago, Ill.

Read at the Seventy-ninth Annual Meeting of The American Association for Thoracic Surgery, New Orleans, La, April 18-21, 1999.

Received for publication April 22, 1999; revisions requested June 26, 1999; revisions received Sept 3, 1999; accepted for publication Oct 28, 1999

Address for reprints: Mark K. Ferguson, MD, Section of Cardiac and Thoracic Surgery, The University of Chicago, 5841 S Maryland Ave, MC5035, Chicago, IL 60637 (E-mail: mferguso@surgery.bsd.uchicago.edu).

Copyright @ 2000 by Mosby, Inc.

0022-5223/2000 $\$ 12.00+0 \quad \mathbf{1 2 / 6 / 1 0 4 1 5 5}$

doi: $10.1067 / \mathrm{mtc} .2000 .104155$ ly appropriate lesions in patients with or without sufficient pulmonary compromise, such that the use of pneumonectomy is contraindicated.

The operative risks of sleeve resection are similar to those of pneumonectomy, ${ }^{1}$ and sleeve resection provides no apparent advantage for long-term survival. Thus the oncologic advantage of sleeve resection over pneumonectomy in patients with sufficient pulmonary reserve is unclear. Impaired function and shortened long-term survival because of the impact of cardiopulmonary compromise have been cited among the considerations that have prompted the decreased use of pneumonectomy in favor of sleeve resection. ${ }^{2}$ To determine the impact of pneumonectomy on long-term survival, we reviewed our experience with pneumonectomy in the treatment of lung cancer and analyzed its influence on survival compared with that of standard lobar resection.

\section{Methods}

We retrospectively reviewed the cases of patients with initial primary lung cancer who underwent major lung resection at The University of Chicago Hospitals between January 1980 
and June 1998. The patient treatment methods and techniques of data collection have been described previously. ${ }^{3}$ Patient evaluation included a history and physical examination, posteroanterior and lateral chest radiographs, and blood tests including a complete blood cell count and serum chemistry evaluations. Computed tomographic (CT) scans of the chest and upper abdomen (including the liver and adrenal glands) were done routinely beginning in 1983. Brain CT scans and bone scintiscans were done in cases of bone pain or those with neurologic symptoms or signs and routinely in patients with T3 primary tumors or with stage IIIA or more advanced cancers. Pulmonary function tests including a calculation of single-breath diffusing capacity for carbon monoxide were done routinely. All patients had a preoperative or intraoperative bronchoscopic examination. Cervical mediastinoscopy or parasternal mediastinotomy were routinely done in patients with pathologically enlarged mediastinal lymph nodes on the CT scan and in patients with suspected T3 disease and were also done in selected other patients.

All patients were treated according to the prevailing protocols at the time of presentation. Patients with clinical stage I and stage II non-small cell lung cancers underwent thoracotomy, lung resection, and mediastinal nodal sampling as primary therapy, and the latter group normally received postoperative radiotherapy and chemotherapy. Some patients with stage IIIA or IIIB lung cancer, so classified on the basis of mediastinal nodal involvement, were treated with preoperative radiation therapy and chemotherapy in conjunction with lung resection. Other patients with stage IIIA lung cancer on the basis of the presence of T3 primary lung cancer without apparent lymph node enlargement were treated by surgical resection initially. Patients with N2 disease discovered at operation had postoperative adjuvant chemotherapy and radiotherapy. All cancers were staged at a weekly chest oncology conference on the basis of the final pathologic diagnosis with use of the American Joint Committee for Cancer Staging staging system. ${ }^{4}$

Operative complications were classified as pulmonary (postoperative mechanical ventilation for $>24$ hours or reintubation for ventilatory support after the day of the operation; pneumonia defined as fever, leukocytosis, and pulmonary infiltrate necessitating antibiotic therapy; air leak from thoracostomy tubes for more than 7 days after the operation; and lobar collapse on postoperative chest radiograph), cardiovascular (new requirements for $\beta$-blockers, calcium channel inhibitors, or vasodilating agents; the need for postoperative inotropic support other than renal dose dopamine; pulmonary embolism; myocardial infarction; and arrhythmia), other (wound infection, empyema, recurrent nerve injury, bronchopleural fistula, and other miscellaneous conditions), and death. Operative mortality was defined as death during hospitalization for lung resection or any death within 30 days of the operation.

Follow-up was done through periodic clinic visits until the patient's death. In some patients annual contact with the treating physician and/or the patient was done through our institutional cancer registry. Follow-up was complete (to death or to within 1 year of analysis in survivors) in 384 (87\%) of 442 patients: 291 (86\%) of 340 patients undergoing lobectomy/ bilobectomy and $93(91 \%)$ of 102 patients undergoing pneumonectomy $(P=.14)$.

Cases were evaluated for demographic, surgical, and pathologic variables, and the distributions of these variables were compared between types of operations with the $\chi^{2}$ test for discrete variables and the Student $t$ test for continuous variables (see Table I). The risk of operative mortality was analyzed initially by univariate analysis. Variables that had a $P$ value $<.15$ were further evaluated with the use of backwards elimination, multivariable, logistic regression analysis. Survival was measured from the date of operation and survivorship calculated according to the Kaplan-Meier method. ${ }^{5}$ Confidence intervals (CI) for median survival time were calculated as described by Brookmeyer and Crowley. ${ }^{6}$ Differences in survival between groups were tested for significance by the log-rank test. ${ }^{7}$ A Cox proportional hazards model was fit to examine and adjust for the effects of surgical treatment and other covariates on survival. ${ }^{8}$ Because there were a number of missing values for some variables, the Cox proportional hazards models were re-fit imputing operative-group specific mean values for the missing variables. All analyses were done with either the Minitab 10.51 (Minitab, Inc, State College, Pa) or Systat 8.0 (SPSS, Inc, Chicago, Ill) programs. Data are expressed as mean $\pm \mathrm{SD}$.

\section{Results}

Major lung resections were done in 442 patients with non-small cell lung cancer. There were 259 men and 183 women with a mean age of $62.6 \pm 10.4$ years (range 35-87 years). Patients undergoing pneumonectomy were younger, had a lower serum albumin concentration, a lower forced vital capacity expressed as a percent of predicted, a lower forced expiratory volume in $1 \mathrm{sec}-$ ond expressed as a percent of predicted $\left(\mathrm{FEV}_{1} \%\right)$, and a higher incidence of preoperative radiotherapy than patients who underwent lobectomy or bilobectomy (Table I). Pneumonectomy was done more often for squamous cell cancer than for other histologic types (Table II). Patients undergoing pneumonectomy had more advanced $\mathrm{T}$ stage, $\mathrm{N}$ stage, and overall stage than did those undergoing lobectomy/bilobectomy.

The perioperative pulmonary complication rate was higher for patients undergoing lobectomy/bilobectomy $(101 / 339 ; 30 \%$ [95\% CI 25\%-35\%]) than for those undergoing pneumonectomy $(16 / 101 ; 16 \%$ [9\%-23\%]; $P=.005)$, largely because of the incidence of persistent air leak in the former group. In contrast, the cardiovascular complication rate was higher for patients undergoing pneumonectomy $(29 / 96 ; 30 \%$ [21\%-39\%]), primarily because of a higher incidence of arrhythmias than in the lobectomy/bilobectomy group (69/325; $21 \%$ [17\%-26\%]; $P=.041$ ). 
Table I. Clinical characteristics of patients undergoing major resection for non-small cell lung cancer

\begin{tabular}{|c|c|c|c|c|}
\hline & All patients & Lobectomy/bilobectomy & Pneumonectomy & $\mathrm{P}$ value \\
\hline Age (y) & $62.6 \pm 10.0(442)$ & $63.1 \pm 10.2(340)$ & $60.8 \pm 9.1(102)$ & .027 \\
\hline Men & $259 / 442 ; 59 \%$ & $191 / 340 ; 56 \%$ & $68 / 102 ; 67 \%$ & .059 \\
\hline Smoking history & $419 / 441 ; 95 \%$ & $324 / 339 ; 96 \%$ & $95 / 102 ; 93 \%$ & .3 \\
\hline Diabetes & $58 / 442 ; 13 \%$ & $50 / 340 ; 15 \%$ & $8 / 102 ; 8 \%$ & .072 \\
\hline Hypertension & $140 / 440 ; 32 \%$ & $115 / 340 ; 34 \%$ & $25 / 100 ; 25 \%$ & .096 \\
\hline Prior MI & $50 / 437 ; 11 \%$ & $40 / 338 ; 12 \%$ & $10 / 99 ; 10 \%$ & .6 \\
\hline Preoperative radiotherapy & $30 / 347 ; 9 \%$ & $16 / 277 ; 6 \%$ & $14 / 70 ; 20 \%$ & $<.001$ \\
\hline Preoperative chemotherapy & $9 / 339 ; 3 \%$ & $7 / 266 ; 3 \%$ & $2 / 64 ; 3 \%$ & .8 \\
\hline Performance status & $9.2 \pm 1.5(430)$ & $9.2 \pm 1.5(332)$ & $9.4 \pm 1.3(98)$ & .2 \\
\hline Serum creatinine (mg/dL) & $1.11 \pm 0.98(263)$ & $1.14 \pm 1.08(216)$ & $1.02 \pm 0.27(47)$ & .14 \\
\hline Serum hemoglobin (gm/dL) & $13.1 \pm 1.6(273)$ & $13.2 \pm 1.6(227)$ & $12.9 \pm 1.9(46)$ & .3 \\
\hline Serum albumin $(\mathrm{gm} / \mathrm{dL})$ & $4.00 \pm 0.48(349)$ & $4.04 \pm 0.48(266)$ & $3.87 \pm 0.46(83)$ & .005 \\
\hline $\mathrm{Po}_{2}(\mathrm{~mm} \mathrm{Hg})$ & $78.2 \pm 11.3(352)$ & $78.4 \pm 11.5(268)$ & $77.4 \pm 10.9(84)$ & .4 \\
\hline $\mathrm{PCO}_{2}(\mathrm{~mm} \mathrm{Hg})$ & $38.0 \pm 4.2(352)$ & $38.1 \pm 4.1(268)$ & $37.6 \pm 4.5(84)$ & .3 \\
\hline FVC (L) & $3.22 \pm 0.89(432)$ & $3.25 \pm 0.91(334)$ & $3.10 \pm 0.82(98)$ & .12 \\
\hline $\mathrm{FVC} \%$ & $86.6 \pm 17.9(407)$ & $88.2 \pm 17.9(324)$ & $80.4 \pm 16.6(83)$ & $<.001$ \\
\hline $\mathrm{FEV}_{1}(\mathrm{~L})$ & $2.22 \pm 0.70(432)$ & $2.24 \pm 0.73$ & $2.15 \pm 0.58$ & .2 \\
\hline $\mathrm{FEV}_{1} \%$ & $83.0 \pm 21.0(407)$ & $84.3 \pm 21.6(324)$ & $78.0 \pm 17.7$ & .007 \\
\hline DLCO $\%$ & $86.2 \pm 22.0(366)$ & $85.4 \pm 20.9(291)$ & $89.3 \pm 25.7(75)$ & .2 \\
\hline
\end{tabular}

Numbers in parentheses indicate the number of patients for whom data were available. Performance status was graded on a scale of 10 to 1 . $M I$, Myocardial infarction; $F V C$, forced vital capacity; $F V C \%$, forced vital capacity expressed as a percent of predicted; $D L C O \%$, diffusing capacity of carbon monoxide expressed as a percent of predicted.

Table II. Histologic type and pathologic staging in patients undergoing major resection for non-small cell lung cancer

\begin{tabular}{|c|c|c|c|c|}
\hline & All patients (442) & Lobectomy/bilobectomy (340) & Pneumonectomy (102) & $\mathrm{P}$ value \\
\hline Histology & & & & $<.001$ \\
\hline Squamous cell & $200(45 \%)$ & $128(38 \%)$ & $72(71 \%)$ & \\
\hline Adenocarcinoma & $196(44 \%)$ & $173(51 \%)$ & $23(23 \%)$ & \\
\hline Other & $46(11 \%)$ & $39(12 \%)$ & $7(7 \%)$ & \\
\hline T stage & & & & $<.001$ \\
\hline 1 & $143(33 \%)$ & $131(39 \%)$ & $12(12 \%)$ & \\
\hline 2 & $204(47 \%)$ & $151(45 \%)$ & $53(54 \%)$ & \\
\hline 3 & $73(17 \%)$ & $48(14 \%)$ & $25(25 \%)$ & \\
\hline 4 & $17(4 \%)$ & $8(2 \%)$ & $9(9 \%)$ & \\
\hline Unknown & 5 & 2 & 3 & \\
\hline $\mathrm{N}$ stage & & & & $<.001$ \\
\hline 0 & $247(57 \%)$ & $221(65 \%)$ & $26(26 \%)$ & \\
\hline 1 & $98(22 \%)$ & $59(17 \%)$ & $39(39 \%)$ & \\
\hline 2,3 & $92(21 \%)$ & $58(17 \%)$ & $34(34 \%)$ & \\
\hline Unknown & 5 & 2 & 3 & \\
\hline Stage & & & & $<.001$ \\
\hline I & $206(47 \%)$ & $194(57 \%)$ & $12(12 \%)$ & \\
\hline II & $101(23 \%)$ & $60(18 \%)$ & $41(41 \%)$ & \\
\hline III & $124(28 \%)$ & $77(23 \%)$ & $47(47 \%)$ & \\
\hline IV & $10(2 \%)$ & $9(3 \%)$ & $1(1 \%)$ & \\
\hline Unknown & 1 & 0 & 1 & \\
\hline
\end{tabular}

The overall operative mortality was 36 of $442(8.1 \%$ [5.6\%-11\%]) and was higher in the pneumonectomy group $(12 / 102 ; 12 \%$ [5.5\%-18\%]) than in the lobectomy/bilobectomy group (24/340; $7.0 \%$ [4.3\%-9.7\%]), but the difference did not reach statistical significance $(P=.13)$. Multivariable logistic regression analysis revealed preoperative hypertension and single-breath diffusing capacity expressed as a percent of predicted (DLCO\%) to be the best determinants of operative mortality, with odds ratios of 2.6 (1.3-5.2) for hypertension and $1.1(1.0-1.2)$ for a 10-point decrease in $\mathrm{DLCO} \%$. The mortality rate decreased from $8.8 \%$ dur- 
ing the period 1980 to 1989 to $7.5 \%$ during the period 1990 to $1998(P=.6)$. The mortality rates for lobectomy/bilobectomy during these periods did not change $(10 / 166$ or $6.0 \%$ [2.4\%-9.6\%] vs $14 / 173$ or $8.1 \%$ [4.0\%-12\%]; $P=.5$ ), whereas the mortality rate decreased substantially for pneumonectomy $(11 / 74$ or $15 \%$ [6.9\%-23\%] vs $1 / 28$ or $3.6 \%[0 \%-10 \%] ; P=.14$ ). The relative rate of pneumonectomy decreased between the two periods $(74 / 240$ or $31 \%$ [25\%-37\%] vs $28 / 201$ or $14 \%$ [9.1\%-19\%]; $P<.001)$.

The mean follow-up interval was $40.5 \pm 45.9$ months. Overall median and 5-year survivals for lobectomy/ bilobectomy were significantly greater than those for pneumonectomy (Table III; Fig 1). Median and 5-year survivals were related to pathologic stage and histologic type (Table III; Fig 2). Cox proportional hazards estimation of survival using the covariates histologic type (classified as squamous cell carcinoma, adenocarcinoma, or other), age, sex, hypertension, preoperative radiation therapy, performance status, serum albumin concentration, $\mathrm{FEV}_{1} \%$, year of operation, type of operation, primary tumor $(\mathrm{T})$ status, and regional node (N) status (stages I, II, and III only) demonstrated T status, $\mathrm{N}$ status, age, performance status, and $\mathrm{FEV}_{1} \%$ to be statistically significant covariates, whereas the type of operation did not achieve significance after adjusting for these variables (Table IV). An analysis done that examined only operative survivors also demonstrated $\mathrm{T}$ status, $\mathrm{N}$ status, age, performance status, and $\mathrm{FEV}_{1} \%$ to be significant covariates, whereas the type of operation did not achieve significance (Table IV). These analyses excluded patients with missing data. However, reanalyses using the imputed values demonstrated no significant effect of type of operation on survival (hazard ratios of 1.02 [0.73-1.42] and 1.19 [0.84-1.69] for all patients and for operative survivors, respectively).

Because survival among patients with stage I disease was more favorable for the patients undergoing pneumonectomy, potentially skewing the analysis of an operation typically done to treat regionally advanced disease, additional analyses were done with only data from patients with stage II or III disease. Using the same covariates listed previously, Cox proportional hazards estimation of survival demonstrated $\mathrm{T}$ status, $\mathrm{N}$ status, age, and $\mathrm{FEV}_{1} \%$ to be statistically significant risk factors, whereas the type of operation did not achieve statistical significance (Table V). An analysis restricted to operative survivors also demonstrated $\mathrm{T}$ status, $\mathrm{N}$ status, age, and $\mathrm{FEV}_{1} \%$ to be significant covariates, whereas the type of operation again did not achieve significance (Table V). Reanalyses using the imputed values yielded no significant effect of type of

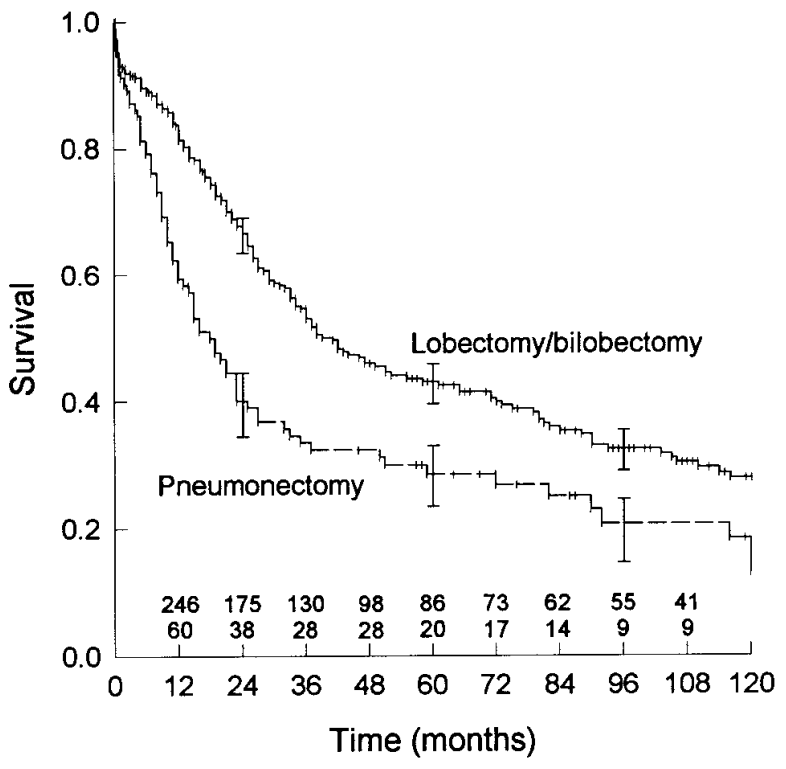

Fig 1. Kaplan-Meier survival curves for patients undergoing lobectomy/bilobectomy or pneumonectomy, all stages combined $(P<.001$ by log-rank). Vertical bars indicate standard error. Numbers at bottom indicate patients at risk at yearly intervals for lobectomy/bilobectomy (top number) and pneumonectomy (bottom number).

operation on survival (hazard ratios of 1.07 [0.76-1.51] and $1.07[0.74-1.56]$ for all patients and for operative survivors, respectively).

\section{Discussion}

The appropriate extent of parenchymal resection for the treatment of lung cancer is determined by tumor location, tumor stage, pulmonary reserve, and a variety of other factors including patient age and performance status. Although the use of pneumonectomy to treat centrally located or regionally advanced lung cancers is standard for patients with adequate pulmonary reserve, the use of sleeve resection techniques for selected patients from this population is growing. The advantages of parenchyma-sparing techniques for patients with limited pulmonary reserve are obvious, and reports have documented that the spared parenchyma functions appropriately. ${ }^{2,9}$ However, the risk of complications specific to parenchyma-sparing procedures is not trivial and includes a local recurrence rate of $10 \%$, benign strictures or stenoses in $5 \%$ of patients, and bronchial fistula formation in $6 \%$ of patients. ${ }^{1}$ Considering these risks, the relative advantages of parenchyma-sparing operations in patients with sufficient pulmonary reserve to permit pneumonectomy are unclear.

Early reports suggested that pneumonectomy was 

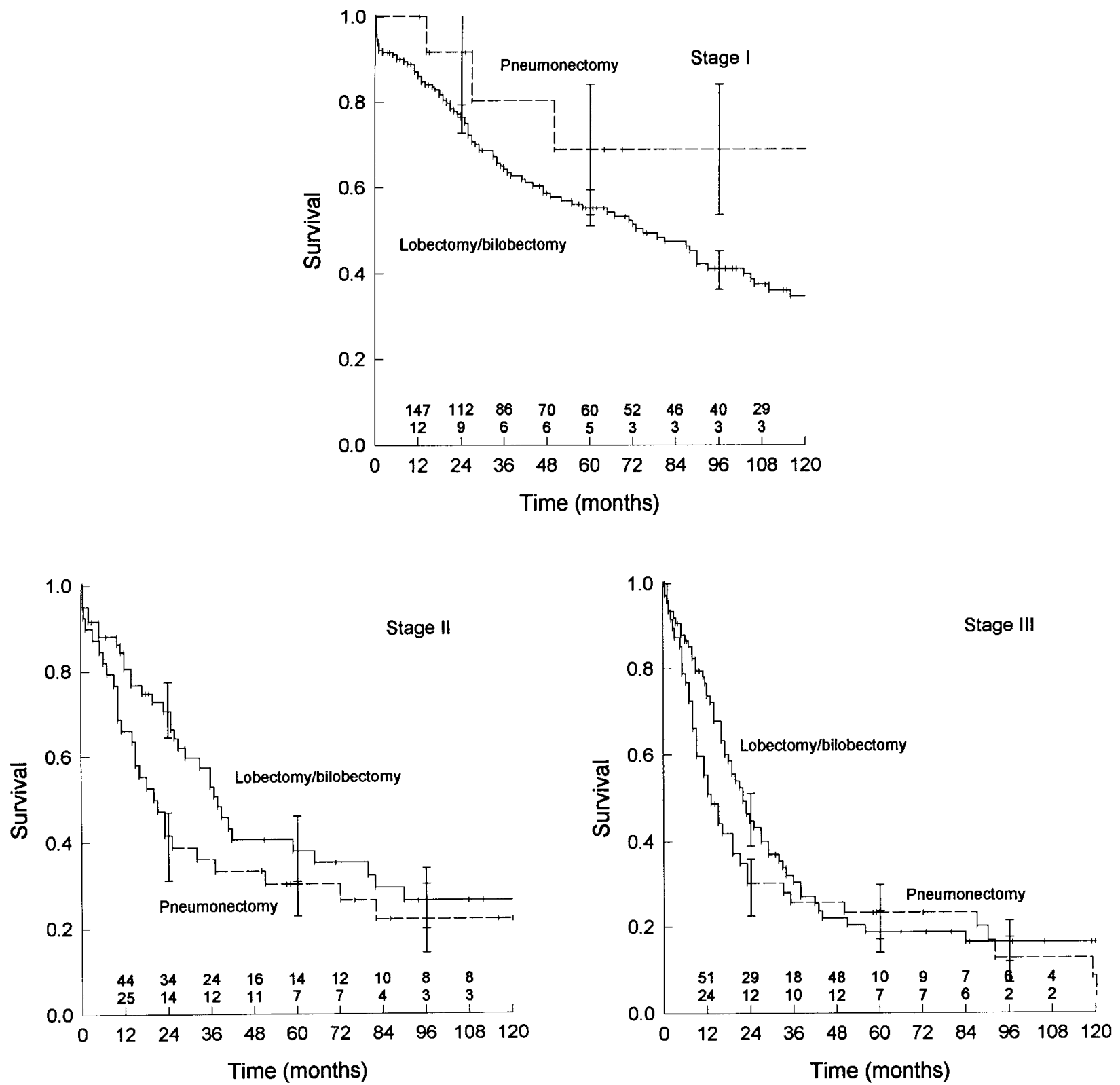

Fig 2. Kaplan-Meier survival curves for patients undergoing lobectomy/bilobectomy or pneumonectomy classified according to pathologic stage. The log-rank test was used to compare curves within each stage. Vertical bars indicate standard error. Numbers at bottom indicate patients at risk at yearly intervals for lobectomy/bilobectomy (top number) and pneumonectomy (bottom number).

associated with important long-term consequences that affected quality of life and possibly long-term survival. These consequences included decreased diffusing capacity and elevated pressures in the right side of the heart during exercise in most patients and progression of emphysema and the development of pulmonary hypertension resulting in cor pulmonale in some patients. ${ }^{10}$ More recent research has confirmed these observations while providing a sound physiologic basis for the findings. ${ }^{11}$ Clinical experience with pneumonectomy during the past several decades, in conjunction with improved methods of patient selection for major lung resection, has reduced operative mortality and morbidity. Nevertheless, concern persists regarding the long-term consequences of pneumonectomy. The current analysis was done to determine 
Table III. Median and 5-year survival after major resection for non-small cell lung cancer

\begin{tabular}{|c|c|c|c|c|c|c|c|}
\hline & \multicolumn{2}{|c|}{ All patients } & \multicolumn{2}{|c|}{ Lobectomy/bilobectomy } & \multicolumn{2}{|c|}{ Pneumonectomy } & \multirow[b]{2}{*}{$\mathrm{P}$ value ${ }^{*}$} \\
\hline & Median (mo) & Five-year (\%) & Median (mo) & Five-year (\%) & Median (mo) & Five-year $(\%)$ & \\
\hline \multicolumn{8}{|l|}{ Stage } \\
\hline I & $75(55-101)$ & $56(48-64)$ & $73(48-101)$ & $55(47-63)$ & N/A & N/A & .19 \\
\hline II & $28(21-39)$ & $32(22-42)$ & $36(26-51)$ & $35(21-49)$ & $18(11-25)$ & $26(11-41)$ & .05 \\
\hline III & $18(14-22)$ & $20(12-28)$ & $21(17-27)$ & $18(8-27)$ & $12(9-16)$ & $21(9-33)$ & .07 \\
\hline \multicolumn{8}{|l|}{ Histology } \\
\hline Squamous cell & $27(23-35)$ & $33(26-40)$ & $32(26-41)$ & $33(24-42)$ & $19(11-27)$ & $30(19-42)$ & .068 \\
\hline Adenocarcinoma & $36(29-64)$ & $43(35-51)$ & $46(34-79)$ & $46(38-55)$ & $14(9-19)$ & $18(2-34)$ & $<.001$ \\
\hline Other cell types & 74 (31-N/A) & $54(35-74)$ & 92 (31-N/A) & $58(35-80)$ & 20 (6-N/A) & N/A & .3 \\
\hline All patients & $34(27-41)$ & $39(34-44)$ & $38(34-51)$ & $43(36-49)$ & $17(12-21)$ & $30(20-40)$ & $<.001$ \\
\hline
\end{tabular}

Numbers in parentheses indicate $95 \% \mathrm{CI}$; not available (N/A) represents values that have not yet been reached or are not calculable.

*Lobectomy/bilobectomy vs pneumonectomy (log rank test).

Table IV. Hazard ratios for covariates of survival after resection for non-small cell lung cancer

\begin{tabular}{lccc}
\hline & Hazard ratio & $95 \%$ CI & P value \\
\hline All patients $(\mathrm{n}=429)$ & & & \\
T2 vs T1 & 1.36 & $1.00-1.85$ & .051 \\
T3, 4 vs T1 & 1.72 & $1.19-2.48$ & .004 \\
N1 vs N0 & 1.97 & $1.44-2.70$ & $<.001$ \\
N2, 3 vs N0 & 2.48 & $1.81-3.40$ & $<.001$ \\
Age $^{*}$ & 1.35 & $1.18-1.55$ & $<.001$ \\
Performance status $^{\dagger}$ & 1.26 & $1.07-1.49$ & .006 \\
FEV $_{1} \%^{\ddagger}$ & 1.06 & $1.03-1.10$ & .001 \\
Operation $^{\S}$ & 1.12 & $0.83-1.50$ & .45 \\
Operative survivors $(\mathrm{n}=396)$ & & & \\
T2 vs T1 & 1.30 & $0.94-1.81$ & .11 \\
T3, 4 vs T1 & 1.69 & $1.14-2.49$ & .009 \\
N1 vs N0 & 2.10 & $1.50-2.94$ & $<.001$ \\
N2, 3 vs N0 & 2.84 & $2.03-3.96$ & $<.001$ \\
Age & 1.35 & $1.16-1.57$ & $<.001$ \\
Performance status & 1.24 & $1.03-1.49$ & .022 \\
FEV ${ }_{1} \%$ & 1.07 & $1.03-1.11$ & .001 \\
Operation & 1.10 & $0.80-1.51$ & .56 \\
\hline
\end{tabular}

"Age: 10-year increase.

'Performance status: 3-point decrease.

${ }^{*} \mathrm{FEV}_{1} \%$ : 10-point decrease.

SOperation: pneumonectomy rather than lobectomy/bilobectomy.

whether pneumonectomy is an independent factor affecting long-term survival after surgical treatment for lung cancer.

Our patient population and operative outcomes were similar to those of most academic medical centers. The operative mortality rate, although in line with rates reported by others, ${ }^{12-14}$ was somewhat higher than in most centers. ${ }^{15-17}$ Interestingly, although the mortality for pneumonectomy decreased somewhat from the first to the second decade covered in our analysis, a similar change was not evident among patients who had lobectomy or bilobectomy. The reasons for this are not clear,
Table V. Hazard ratios for covariates of survival after resection for non-small cell lung cancer for patients with regionally advanced (stages II, III) disease

\begin{tabular}{lccc}
\hline & Hazard ratio & $95 \%$ CI & P value \\
\hline All patients $(\mathrm{n}=223)$ & & & \\
T2 vs T1 & 1.69 & $1.02-2.81$ & .043 \\
T3, 4 vs T1 & 2.31 & $1.32-4.03$ & .003 \\
N1 vs N0 & 2.38 & $1.36-4.18$ & .003 \\
N2, 3 vs N0 & 2.87 & $1.60-5.14$ & $<.001$ \\
Age $^{*}$ & 1.22 & $1.02-1.46$ & .025 \\
FEV $_{1} \%^{\dagger}$ & 1.07 & $1.02-1.13$ & .005 \\
Operation $^{*}$ & 1.21 & $0.88-1.68$ & .24 \\
Operative survivors $(\mathrm{n}=204)^{\text {T2 vs T1 }}$ & & & \\
T3, 4 vs T1 & 1.70 & $1.00-2.89$ & .05 \\
N1 vs N0 & 2.25 & $1.25-4.05$ & .007 \\
N2, 3 vs N0 & 2.29 & $1.26-4.17$ & .007 \\
Age & 2.98 & $1.60-5.55$ & .001 \\
FEV ${ }_{1} \%$ & 1.24 & $1.03-1.50$ & .025 \\
Operation & 1.08 & $1.03-1.14$ & .003 \\
\hline
\end{tabular}

*Age: 10-year increase.

${ }^{\dagger} \mathrm{FEV}_{1} \%$ : 10-point decrease.

Operation: pneumonectomy rather than lobectomy/bilobectomy.

but the findings may be related to local referral patterns to tertiary care centers.

We found the long-term survival for patients undergoing pneumonectomy to be significantly shorter than that for those undergoing lobectomy/bilobectomy, confirming findings of previous reports based on univariate analyses. ${ }^{18,19}$ However, the multivariable analysis demonstrated that the type of operation was not a significant independent determinant of long-term survival, as has been suggested by others. ${ }^{20,21}$ Important covariates for long-term survival included patient age, preoperative spirometry, and $\mathrm{T}$ and $\mathrm{N}$ status. Age has been 
identified previously as a determinant of long-term survival after major lung resection. ${ }^{22,23}$

The finding that preoperative spirometry is a predictor of long-term survival after major resection for lung cancer has not been widely reported. That survival is unfavorably influenced at the low extremes of spirometric measurements in populations with chronic obstructive pulmonary disease is well known. ${ }^{24,25}$ Recent experience with lung volume reduction operations for end-stage emphysema has confirmed these findings. ${ }^{26}$ Our results extend the evidence for a relationship between spirometry and long-term survival to include patients with less marked impairments in air flow. The effect of spirometry on long-term survival is relatively small compared with the effects of pathologic stage and age. Nevertheless, further investigation of this relationship is warranted.

Our results suggest that pneumonectomy can be done with acceptable incidences of operative morbidity and mortality and that this extent of resection does not have an important effect on long-term survival. However, the CIs were wide and therefore larger studies are needed. Moreover, despite adjustment for observed covariates, the effects of patient selection and other potential confounding factors limit the conclusions that can be drawn from this retrospective study, suggesting that randomized prospective trials would be needed to definitively address this issue.

These findings must not be taken to suggest that the use of pneumonectomy should be widely expanded in patients undergoing resection to treat lung cancer. Judicious assessment of the appropriate extent of operation remains a vital element in the surgical management of lung cancer. Complete resection remains the hallmark of a successful operation. An important area of controversy is the appropriate management of centrally located cancers in patients with sufficient pulmonary reserve to permit pneumonectomy. The selection of a lesser resection such as sleeve lobectomy in such patients might expose them to an increased risk of local recurrence. In such instances, if there is doubt about the completeness of resection, pneumonectomy should be considered.

\section{REFERENCES}

1. Tedder M, Anstadt MP, Tedder SD, Lowe JE. Current morbidity, mortality, and survival after bronchoplastic procedures for malignancy. Ann Thorac Surg 1992;54:387-91.

2. Gaissert HA, Mathisen DJ, Moncure AC, Hilgenberg AD, Grillo HC, Wain JC. Survival and function after sleeve lobectomy for lung cancer. J Thorac Cardiovasc Surg 1996;111:948-53.

3. Ferguson MK, Wang J, Hoffman PC, Haraf DJ, Olak J, Masters GA, et al. Sex-associated differences in survival of patients undergoing resection for lung cancer. Ann Thorac Surg. In press.

4. Mountain CF. Revisions in the international system for staging lung cancer. Chest 1997;111:1710-7.

5. Kaplan EL, Meier P. Nonparametric estimation from incomplete observations. J Am Stat Assoc 1958;53:457-81.

6. Brookmeyer R, Crowley J. A confidence interval for the median survival time. Biometrics 1982;38:29-41.

7. Kalbfleisch JD, Prentice RL. The statistical analysis of failure time data. New York: John Wiley; 1980.

8. Cox DR. Regression models and life tables. J R Stat Soc, Series B 1972;34:187-220.

9. Deslauriers J, Gaulin P, Beaulieu M, Piraux M, Bernier R, Cormier Y. Long-term clinical and functional results of sleeve lobectomy for primary lung cancer. J Thorac Cardiovasc Surg 1986;92:871-9.

10. Burrows B, Harrison RW, Adams WE, Humphreys EM, Long ET, Reimann AF. The postpneumonectomy state. Am J Med 1960; 28:281-97.

11. Hsia CCW, Johnson RI Jr. Physiology and morphology of postpneumonectomy compensation. In: Crystal RG, West JB, editors. The lung: scientific foundations. 2nd ed. Philadelphia: LippincottRaven; 1997. p. 1047-59.

12. Whittle J, Steinberg EP, Anderson GF, Herbert R. Use of Medicare claims data to evaluate outcomes in elderly patients undergoing lung resection for lung cancer. Chest 1991;100:72934.

13. Romano PS, Mark DH. Patient and hospital characteristics related to in-hospital mortality after lung cancer resection. Chest 1992;101:1332-7.

14. Duque JL, Ramos G, Castrodeza J, Cerezal J, Castanedo M, Yuste MG, et al. Early complications in surgical treatment of lung cancer: a prospective, multicenter study. Ann Thorac Surg 1997; 63:944-50.

15. Wahi R, McMurtrey MJ, DeCaro LF, Mountain CF, Ali MK, Smith TL, et al. Determinants of perioperative morbidity and mortality after pneumonectomy. Ann Thorac Surg 1989;48:33-7.

16. Roxburgh JC, Thompson J, Goldstraw P. Hospital mortality and long-term survival after pulmonary resection in the elderly. Ann Thorac Surg 1991;51:800-3.

17. Mizushima Y, Noto H, Sugiyama S, Kusajima Y, Yamashita R, Kashii T, et al. Survival and prognosis after pneumonectomy for lung cancer in the elderly. Ann Thorac Surg 1997;64:193-8.

18. Williams DE, Pairolero PC, Davis CS, Bernatz PE, Payne S, Taylor WF, et al. Survival of patients surgically treated for stage I lung cancer. J Thorac Cardiovasc Surg 1981;82:70-6.

19. Miller DL, McManus KG, Allen MS, Ilstrup DM, Deschamps C, Trastek VF, et al. Results of surgical resection in patients with N2 non-small cell lung cancer. Ann Thorac Surg 1994;57:1095-101.

20. Yano T, Yokoyama H, Inoue T, Asoh H, Tayama K, Ichinose Y. Surgical results and prognostic factors of pathologic N1 disease in non-small cell carcinoma of the lung. J Thorac Cardiovasc Surg 1994;107:1398-402.

21. Al-Kattan K, Sepsas E, Townsend ER, Fountain SW. Factors affecting long term survival following resection for lung cancer. Thorax 1996;51:1266-9.

22. Sorenson JB, Badsberg JH. Prognostic factors in resected stages I and II adenocarcinoma of the lung. J Thorac Cardiovasc Surg 1990;99:218-26.

23. Paesmans M, Sculier JP, Libert P, Bureau G, Dabouis G, Thiraux 
J, et al. Prognostic factors for survival in advanced non-small-cell lung cancer: univariate and multivariate analyses including recursive partitioning and amalgamation algorithms in 1,052 patients. J Clin Oncol 1995;13:1221-30.

24. Anthonisen NR. Prognosis in chronic obstructive pulmonary disease: results from multicenter clinical trials. Am Rev Respir Dis 1989;140:S95-9.

25. Naunheim KS, Ferguson MK. The current status of lung volume reduction operations for emphysema. Ann Thorac Surg 1996;62: 601-12.

26. Brenner M, McKenna RJ Jr, Chen JC, Osann K, Powell L, Gelb $\mathrm{AF}$, et al. Survival following bilateral staple lung volume reduction surgery for emphysema. Chest 1999;115:390-6.

\section{Discussion}

Dr Joel D. Cooper (St Louis, Mo). It is always a bit provocative when something is presented that seems to be a little counterintuitive. I think it was Warren Buffett who said he never invests in anything that he does not understand. Before I buy into the conclusions, I need to understand it a bit more.

You cite a significant risk for sleeve lobectomy but point out that the risk is similar to that for pneumonectomy, and I think in most series it is, usually in the 5\% range. However, I do think that the risk of sleeve lobectomy is not greater than that of pneumonectomy and that the risk of local recurrence in selected patients is not greater, so intuitively one would think that doing a lesser resection would be advantageous.

How often did you use sleeve resection in your overall group of resections during this period? I have always used a benchmark that $5 \%$ to $8 \%$ of all pulmonary resections should probably be sleeve resections, on the basis of reviewing a number of series, so I am curious to know whether you did or did not have a bias for sleeve resection and how widely you employed it.

You looked at death, but clearly quality of life and functional outcome would be important factors in evaluating the difference between lobe and lung resection. Do you have any information on functional outcome or performance data for the patients who did have a lung removed versus those who had a lesser resection?

I am not much of a statistician, and I guess I even have a certain amount of suspicion, but I am a little puzzled. In the manuscript, you did show that stage for stage and cell type for cell type the pneumonectomy survival is much less; both median survival and 5-year survival are less than in the group that had a lesser resection. Is it possible that pneumonectomy really is a significant risk factor but that there is a type 2 error here, namely, that the analysis just did not have enough statistical power to demonstrate that pneumonectomy is a risk factor? Maybe some insight into that could be gained by looking at how many of the deaths were attributable to malignant disease recurrence versus other causes of death. Is there a discrepancy in the death rate from strokes, heart attacks, respiratory failure, and other cardiopulmonary conditions between the two groups that might suggest that pneumonectomy really does have an inherent risk factor?
Finally, you acknowledged a fairly high incidence of death after pneumonectomy in the first part of the series that reduced very significantly in the second half of the series, I think from $15 \%$ down to $3 \%$ or $4 \%$. Was that a response to the high mortality in the first half of the series? In the latter part of your series, do you think that there were patients who did not get an operation at all but who could have had a sleeve resection because of the concern regarding the risk of pneumonectomy?

Dr Ferguson. Those are all excellent questions. I think I would take a little different stance on the risk of local recurrence after sleeve lobectomy versus more standard operations. A recent meta-analysis of sleeve resection versus more standard resections clearly showed that there is a substantial risk, perhaps about $10 \%$, for local recurrence compared with that in more standard resections. Thus the question is, what is the advantage of sleeve resection over more standard operations, and you have to argue that it is quality of life, presumably because of preservation of pulmonary parenchyma. Whether that permits the patient to live longer or whether that provides more of an area for a new lung cancer to develop may be controversial. How those balance out is unknown.

You mentioned that you use $5 \%$ to $8 \%$ of the total number of lung resections as a baseline figure for sleeve lobectomy: our incidence is probably lower than that, more in the range of $1 \%$ to $2 \%$. Because this report covers such a number of years and a wide variety of surgeons, it is difficult to say why that is the case. We are using it in our armamentarium, certainly now, as a standard operation for very specific indications.

I think that quality of life is a very important issue. The information presented here looks only at raw survival. Unfortunately, we have no data regarding quality of life, and I think that needs to be looked into.

The statistics are interesting and challenging. One of the things that we did early on was always to stratify according to stage when we were doing our multivariable analyses. In the initial analysis, patients with stage I disease appeared to do better. We discarded those data and reanalyzed stages II and III alone. We found that some of the effects of the type of operation became apparent when it was looked at that way. One of the issues is that bundling patients into these broad stage categories tends to obscure the effects of the TNM classifications. Therefore, rather than stratifying for stage, we separated the patients according to $\mathrm{T}$ status and $\mathrm{N}$ status, which then eliminated much of the effect of the type of operation in the analysis.

I do not have accurate information regarding cause of death. Our tumor registry categorizes patients according to death from tumor, death from other causes, and unknown, and just looking at those data, it did not appear that there was much difference in the long-term death rate because of recurrent cancer, but whether there is an increased death rate because of cardiopulmonary complications in the pneumonectomy group is not possible to say in our database.

In terms of the selection of patients for pneumonectomy, you probably noticed that the frequency of pneumonectomy did decrease during the second decade of the study. I think this probably did have something to do with patient selection. 
It is conceivable that some patients were denied an operation because of our caution. I do not think it was based necessarily on our perceived high percentage of mortality because we had not really analyzed those data, but maybe it was more of a gut feeling to be a little bit more conservative about the operations.

Dr Malcolm M. DeCamp (Cleveland, Ohio). When you looked at all the different confounding variables, and there are some cases of higher stage disease in the analysis, did you think that the use of adjuvant/neoadjuvant therapy was pretty evenly distributed in the groups of both pneumonectomies and lobectomies for stages II and III disease? Obviously this is going to have an impact on survival as the outcome.

Is it possible that part of the reason the type of operation did not appear statistically significant was that, as you noted, the mortality in the lobectomy group was a little higher than you might predict, certainly in contemporary series? Given that the patients undergoing lobectomy did worse than expected and the patients undergoing pneumonectomy did a little bit better, perhaps you washed out the statistical significance when you looked at the type of operation as a risk factor affecting long-term survival.
Dr Ferguson. We looked at neoadjuvant chemotherapy and neoadjuvant radiation therapy. There were too few patients, only about 30 , who had neoadjuvant chemotherapy to enter into the analysis. We did use neoadjuvant radiation therapy as one of the variables in the multivariable analysis, and that fell out very early as a predictor of long-term mortality. We have not had an opportunity to look at postoperative adjuvant therapy of either type and whether that affects long-term survival.

We repeated the analysis excluding operative mortality because of the concern that you raised about the differential operative mortality possibly confounding the outcome. The results were identical regardless of whether we included or excluded patients with operative mortality.

Dr Douglas J. Mathisen (Boston, Mass). You imply that there may be some advantage conferred by pneumonectomy relative to local recurrence, and maybe you cannot get that information from your tumor registry, but do you have any sense of whether local recurrence was affected by pneumonectomy compared with lobectomy?

Dr Ferguson. No, I am sorry. I do not have the information, and I have not generated a sense about it either.

\section{Online-www.aats.org}

Now you can get The Journal of Thoracic and Cardiovascular Surgery online. The Journal online brings you faster delivery time, easy searching of current and back issues, links to PubMed, AATS, WTSA, and other important sites, and more. Visit the Journal online today.

\section{Receive tables of contents by e-mail}

To receive the tables of contents by e-mail, sign up through our Web site at http://www.mosby.com/jtcvs. Choose E-mail Notification. Simply type your e-mail address in the box and click the Subscription button.

Alternatively, you may send an e-mail message to majordomo@mosby.com. Leave the subject line blank and type the following as the body of your message: subscribe jtcvs_toc.

You will receive an e-mail to confirm that you have been added to the mailing list. Note that table of contents e-mails will be sent out when a new issue is posted to the Web. 